\title{
Ultrasonic Scission of Deoxyribonucleic Acid in Aqueous Solution I. Conditions for Sonication and Molecular Weights of Sonicated Samples
}

\author{
Kiyohiro FuKUdome, Kiwamu YamaOKA, ${ }^{*}$ Kenichiro NiSHIKORI, \\ Takamichi TAKAHASHI, and Osamu YAMAMOTO** \\ Faculty of Science, Hiroshima University, Higashisenda-machi, \\ Naka-ku, Hiroshima 730, Japan \\ ** Research Institute for Nuclear Medicine and Biology, \\ Hiroshima University, Kasumi-machi, Minami-ku, \\ Hiroshima 734, Japan
}

(Received December 11, 1984)

\begin{abstract}
By irradiating ultrasonic wave $(20 \mathrm{kHz})$ to calf thymus deoxyribonucleic acid (DNA) in aqueous solution $\left(2 \mathrm{mg} \mathrm{ml}^{-1}\right.$ containing $\left.0.2 \mathrm{M} \mathrm{NaCl}\right)$ at $0^{\circ} \mathrm{C}$, the molecular weight $\left(M_{w}\right)$ was degraded from $8 \times 10^{6}$ to $c a .2 \times 10^{5}$ without any noticeable denaturation. The dependence of the molecular weight of sonicated DNA on the irradiation intensity was examined by varying ultrasonic energy levels. The molecular weights were remarkably decreased with the increase in ultrasonic power from 25 to $105 \mathrm{~W}$, and reached a steady value $\left(M_{w}=2.4 \times 10^{5}\right)$ at $100-200 \mathrm{~W}$.

KEY WORDS Deoxyribonucleic Acid / Ultrasonic Scission / Molecular Weight / Gel Permeation Chromatography / Gel Electrophoresis / Viscosity /
\end{abstract}

Degradation of polymeric materials by heat, light, ultrasonic wave, radioactive rays, and enzymes has been studied extensively. ${ }^{1-3}$ In particular, the scission mechanism of high polymer by ultrasonic wave is unique in that there exists a lower limit in the degraded molecular weight, as many experimental results indicate. Jellinek and White ${ }^{4,5}$ and Ovenall and his coworkers ${ }^{6,7}$ have proposed models for the mechanism of this ultrasonic scission. Ultrasonic scission has been applied to deoxyribonucleic acid (DNA). ${ }^{8-21}$ For example, Pritchard et al. ${ }^{11}$ and Obrenovitch and Sadron $^{13}$ showed that the molecular weight of sonicated DNA depends on the irradiation intensity of sonic wave. Bertazzoni showed from the analysis of terminal bases of sonicated DNA that no base specificity is associated with ultrasonic scission. ${ }^{21}$ Record et

\footnotetext{
* To whom correspondence should be addressed.
}

$a l .^{16}$ and Godfrey and Eisenberg ${ }^{17,18}$ utilized this special feature of ultrasonic scission to prepare well-defined low molecular weight DNA samples, by sonicating a high molecular weight DNA and by fractionating the degraded samples.

Since the double-helical DNA backbone is semiflexible, the electrooptical properties such as electric moments, birefringence, and dichroism, and the hydrodynamic properties such as rotational relaxation time, mean radius of gyration, and intrinsic viscosity, are all affected by the molecular weights. ${ }^{20,22-25}$ In order to investigate the dependence of these properties on the chain length of DNA in detail, it is necessary to prepare the samples of widely different molecular weights, each of which has a narrow molecular weight distribution. At present, nearly monodisperse DNA samples of various molecular weights become available by the restriction enzyme fragmentation meth- 
ods. $^{25}$ A fairly large amount of a singlebatch DNA sample is, however, required to carry out the aforementioned physicochemical experiments. It is, therefore, important to establish a convenient method for the preparation and purification of sonicated, very short DNA samples.

We have studied the sonication of DNA in this series of work with three objectives: (1) to clarify the relationship between the experimental condition for ultrasonic scission and the molecular weight of sonicated samples, (2) to establish the molecular weight fractionation of sonicated samples and the molecular weight distribution of fractionated samples, and (3) to determine some important physical properties of the fractionated samples with various molecular weights. In this paper, we will report in detail the results of the first of these three objectives.

\section{EXPERIMENTAL}

\section{Materials and Preparation of DNA Solution}

A calf thymus DNA sample with a molecular weight, $M_{w}$, of $5 \times 10^{6}$ was purchased from Worthington Biochemical Corp. (New Jersey, U.S.A.). The protein content was determined to be less than $1 \%$ by the biuret method. ${ }^{26}$ All other chemicals were of reagent grade. A stock DNA (hDNA) solution $\left(2 \mathrm{mg} \mathrm{ml}^{-1}\right)$ containing $0.2 \mathrm{M} \mathrm{NaCl}$ without buffer was prepared with due cautions, as described previously. ${ }^{20}$ The mass concentration of anhydrous DNA (1 mg per ml water) corresponds to the residue concentration $\left(3.03 \times 10^{-3} \mathrm{~mol} \mathrm{dm}^{-3}\right)$, which is photometrically determined at $260 \mathrm{~nm}$ with the molar absorption coefficient $\varepsilon(P)$ of $6400 .^{24}$

\section{Sonication}

The sonication of DNA solutions was performed, according to the general procedure given elsewhere, ${ }^{20}$ with a Tomy Co. Model UR-200P sonicator $(20 \mathrm{kHz}$, the highest power $200 \mathrm{~W}$ ) either with a standard chip or with a
Table I. Conditions of ultrasonic irradiation and the properties of DNA

\begin{tabular}{|c|c|c|c|c|c|c|}
\hline \multirow{2}{*}{ Samples } & \multirow{2}{*}{ Chip $^{a}$} & \multirow{2}{*}{$\frac{p^{\mathrm{b}}}{\mathrm{W}}$} & \multirow{2}{*}{$\frac{t^{\mathrm{c}}}{\mathrm{s}}$} & \multirow{2}{*}{$\frac{[\eta]}{10^{2} \mathrm{~cm}^{3} \mathrm{~g}^{-1}}$} & \multirow{2}{*}{$\frac{V_{\mathrm{e}}^{\mathrm{d}}}{\mathrm{cm}^{3}}$} & \multirow{2}{*}{$\frac{V_{\mathrm{w}}^{\mathrm{d}}}{\mathrm{cm}^{3}}$} \\
\hline & & & & & & \\
\hline I & - & 0 & 0 & 45.5 & $24.8^{e}$ & $3.7^{\mathrm{e}}$ \\
\hline II & $\mathrm{n}$ & 25 & 20 & 43.7 & - & - \\
\hline III & $\mathrm{n}$ & 60 & 60 & 29.5 & - & - \\
\hline IV & $\mathrm{n}$ & 60 & 90 & 15.3 & - & - \\
\hline V & $\mathrm{n}$ & $\dot{25}$ & 1200 & 4.18 & 44.6 & 14.6 \\
\hline VI & $\mathrm{s}$ & 25 & 1200 & 2.83 & 45.9 & 12.5 \\
\hline VII & $\mathrm{n}$ & 60 & 1200 & 2.13 & 47.8 & 11.4 \\
\hline VIII & $\mathrm{s}$ & 60 & 1200 & 2.23 & 46.5 & 11.4 \\
\hline IX & $\mathrm{n}$ & 105 & 1200 & 1.32 & 50.0 & 9.8 \\
\hline $\mathrm{X}$ & s & 105 & 1200 & 2.08 & 48.4 & 11.7 \\
\hline XI & $\mathrm{n}$ & 200 & 1200 & 1.32 & 50.7 & 9.6 \\
\hline
\end{tabular}

a Standard (n) and small (s) chips.

b Nominal irradiation intensity expressed in watts.

c Irradiation time.

d These quantities are defined in text.

e These are only apparent, because hDNA is eluted at void volume.

micro chip attached to the horn. A rosette vessel (the maximum volume $200 \mathrm{ml}$ ) with three side-tubes, through which vigorous convection of the irradiated solution occurs, was placed at $0^{\circ} \mathrm{C}$ in a sufficiently large iced bath. The vessel was cleaned with solvent $(0.2 \mathrm{M}$ $\mathrm{NaCl}, 140 \mathrm{ml}$ ) by ultrasonic irradiation for two minutes. A DNA solution $(60-120 \mathrm{ml})$ was then placed in the vessel, into which helium gas was introduced for fifteen minutes to remove dissolved air. The chip was immersed into the solution about $1 \mathrm{~cm}$ below the level, and the solution was bursted for twenty or thirty seconds at a fixed irradiation intensity, then followed by a five-minute interval for bubbling helium gas. This burst-and-bubbling cycle was repeated for two to forty times. The detailed sonication conditions are given in Table I. A $0.1 \mathrm{M}$ ethylenediaminetetraacetate (disodium salt; $\mathrm{Na}_{2}$ EDTA) solution was added to each sonicated DNA solution by $5 \mathrm{vol} \%$, which was then dialyzed against $0.2 \mathrm{M} \mathrm{NaCl}$ for 5-7 days at $4^{\circ} \mathrm{C}$, by changing a total of 14 liters of the solvent in seven portions. The 


\section{K. FuKudome et al.}

dialyzed solution was stored at $4^{\circ} \mathrm{C}$.

\section{Methods and Measurements}

Viscosity. The intrinsic viscosity of sonicated low molecular weight DNA samples $\left(M_{w}<5.7 \times 10^{5}, \mathrm{~V}-\mathrm{XI}\right)$ was measured with $0.2 \mathrm{M} \mathrm{NaCl}$ solvent at $25 \pm 0.005^{\circ} \mathrm{C}$, by using two single-bulb dilution type Ubbelohde viscometers (the flow times of the solvent are 100 and 272 seconds). For sonicated high molecular weight DNA $\left(M_{w}>5.7 \times 10^{5}\right.$, I-IV solutions, a five-bulb variable gradient dilution type Ubbelohde viscometer ${ }^{27}$ (the flow times: $152,121,122$, and 154 seconds and the capillary dimensions: the inner bore $0.7 \mathrm{~mm}$, the diameter of the spiral $c a .12 \mathrm{~cm}$ with four turns, and the total length $154 \mathrm{~cm}$ ) was used. With this viscometer, both concentrations and shear gradients could be extrapolated to zero. It should be noted that the above two viscometers were tested for a fractionated sample, and an exactly same value $\left(400 \times 10^{2} \mathrm{~cm}^{3} \mathrm{~g}^{-1}\right.$, the estimated $M_{w}=5.5 \times 10^{5}$ ) was obtained.

Melting Profile. The absorbance of DNA solutions containing $10 \mathrm{mM} \mathrm{NaCl}$ was measured in a 1-cm long quartz cell on a Hitachi Model 139 UV-VIS spectrophotometer. The temperature of a sample solution was varied from 5 up to $95^{\circ} \mathrm{C}$, by circulating temperature-regulated water. The temperature was monitored with a thermistor bead, which was directly immersed into the reference cell. The change in the weight of a sample solution inside the cell was negligibly small before and after a heating cycle.

Gel Permeation Chromatography. The GPC of sonicated DNA samples was performed with a column (Pharmacia Fine Chemicals, K16) packed with Sephacryl S-1000 Superfine gel (the height $35 \mathrm{~cm}$ ) at $20^{\circ} \mathrm{C}$ in an incubator. A $0.6-\mathrm{ml}$ DNA solution containing $0.2 \mathrm{M}$ $\mathrm{NaCl}$ was injected gently into the bottom of the column, and eluted with $0.2 \mathrm{M} \mathrm{NaCl}$ at a flow rate of about $8 \mathrm{ml} \mathrm{h}^{-1}$. The absorbance of this eluted sample solution was monitored at $260 \mathrm{~nm}$ on a Japan Spectroscopic Co.
UVIDEC-100II spectrophotometer and recorded on a Rikadenki Model R-201 pen recorder.

Agarose Gel Electrophoresis. Electrophoresis of sonicated DNA samples was carried out with a Bethesda Research Laboratries, Inc. Model V16 vertical gel electrophoresis system, together with an $\mathrm{M} \& \mathrm{~S}$, Inc. Model M30-SR power supply. Agarose (BRL, Inc. electrophoresis grade) was dissolved to be $1.2 \mathrm{wt} \%$ in a buffer solution for electrophoresis at $\mathrm{pH} 7.8$ (40 mM Tris, $20 \mathrm{mM}$ sodium acetate, and $2 \mathrm{mM} \quad \mathrm{Na}_{2}$ EDTA). Each 50- $\mu$ l sonicated DNA solution was loaded onto each slot of an agarose gel plate (ca. $3 \mathrm{~mm}$ thick), which is equipped with seven slots-six for samples and one for the standard molecular weight marker. The plate was run vertically in the buffer solution at $150 \mathrm{~V}$ for two hours in an ice bath. The standard molecular weight markers consist of the BRL, Inc. HindIII digest of $\lambda$ phage DNA (fragment sizes in base pairs; 23700, 9500, 6600, 4300, 2100, 1900, and 590) and Hae III digest of $\phi \mathrm{X} 174$ DNA (fragment sizes in base pairs; 1353, 1078, 872, 603, 310, 281, 271, 234, and 194). After electrophoresis, the gel plate was immersed into an ethidium bromide solution for staining for fifteen minutes at room temperature. The electrophoretic pattern was monitored on the fluorescence light at $590 \mathrm{~nm}$ (excited at $340 \mathrm{~nm}$ ), by scanning the plate on the chromatoscanner attached to a Hitachi $650-10 \mathrm{~S}$ fluorescence spectrophotometer. ${ }^{28}$

\section{RESULTS AND DISCUSSION}

\section{Sonication}

The conditions for ultrasonic irradiation of stock DNA solutions, the intrinsic viscosity of sonicated DNA (sDNA) solutions, the elution volume, and the half intensity width are all summarized in Table I. No clear effect of the shape of the sonicator chip on sonication was conceivable, as indicated by the observed vis- 
cosity of sonicated samples (compare IX with $\mathrm{X}$ and $\mathrm{V}$ with VI). The viscosity decreases greatly with the increase in both time and intensity of irradiation (the detail will be given in the later section). The elution volume $V_{\mathrm{e}}$ is defined as the total volume of the eluent which flows through the column between the start of elution and the appearance of the peak absorbance on chromatogram, while the half intensity width $V_{\mathrm{w}}$ is defined as the volume difference between two volumes (corresponding to the width) at which the maximum absorbance decreases by half. Values of $V_{\mathrm{e}}$ for irradiated samples increase with the increase in irradiation intensity, indicating that the molecular weights are degraded accordingly. At the same time, values of $V_{\mathrm{w}}$ also decrease with the increase in irradiation intensity, indicating that the distribution of molecular weight becomes narrower.

\section{Melting Curves}

Figure 1 shows melting curves of two sonicated DNA solutions (IX and XI) and the original DNA solution (I). The fractional absorbance change, defined as $f=\left(A-A_{\mathrm{n}}\right) /$ $\left(A_{\mathrm{d}}-A_{\mathrm{n}}\right)$, is plotted against temperature, where $A_{\mathrm{n}}$ is the absorbance of a DNA sample at $260 \mathrm{~nm}$ and at $20^{\circ} \mathrm{C}, A_{\mathrm{d}}$ is the absorbance at the same wavelength and at $95^{\circ} \mathrm{C}$, and $A$ is the absorbance at a given temperature. In spite of a large difference in intrinsic viscosities, the profiles of the melting curves in Figure 1 are very similar to each other. Nevertheless, it is noted that a highly irradiated sample melts at a slightly lower temperature, yielding a lower value of $T_{\mathrm{m}}$, which is the temperature where $f=0.5$. This result should be attributed to the lowering of the cooperativity because of the decrease in chain length but not to the chemical effect of sonication. ${ }^{24}$ The hyperchromicity, $H$, defined as $H=\left(A_{\mathrm{d}}-A_{\mathrm{n}}\right) / A_{\mathrm{n}}$, of those samples in Figure 1 is in a range of $39-40 \%$. This result may therefore be taken as evidence that the doublehelical structure is not destroyed by sonication

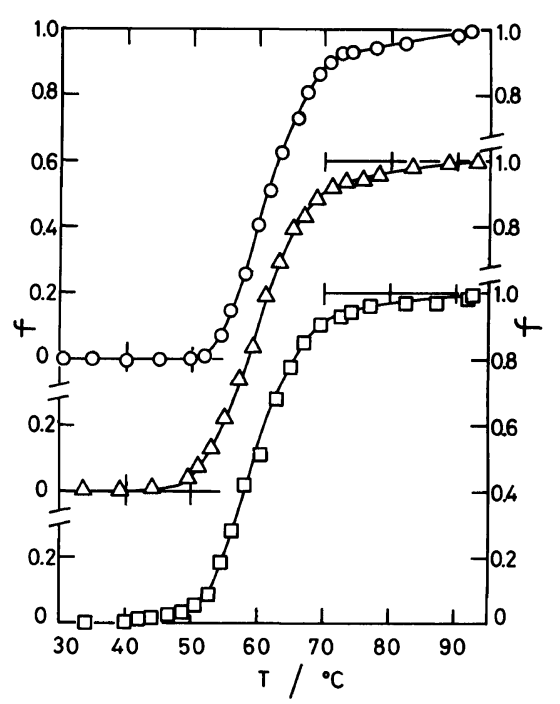

Figure 1. Melting curves of DNA in $10 \mathrm{mM} \mathrm{NaCl}$ solutions. $\bigcirc$, unirradiated calf thymus DNA (sample I, $\left.H=40 \%, T_{\mathrm{m}}=61{ }^{\circ} \mathrm{C}\right) ; \triangle$, sonicated DNA at $105 \mathrm{~W}$ (sample IX, $H=39 \%, T_{\mathrm{m}}=60^{\circ} \mathrm{C}$ ); $\square$, sonicated DNA at $200 \mathrm{~W}$ (sample XI, $H=39 \%, T_{\mathrm{m}}=59^{\circ} \mathrm{C}$ ).

nor some single-stranded regions of considerable length are formed in the double helix. Thus, it is clear that the calf thymus DNA can be scissored by ultrasonic irradiation, the double-helical structure being kept intact.

\section{Gel Permeation Chromatograms and Gel Electrophoresis Patterns}

Gel Permeation Chromatograms. In order to examine the effect of irradiation time on the molecular weight of degraded samples, small portions of an hDNA solution were removed from the rosette vessel at several time intervals during irradiation, and chromatographed. The chromatograms are shown in Figure 2, where the absorbance at $260 \mathrm{~nm}, A_{260}$, is plotted against the volume of eluent $V$. Each chromatogram is normalized, so that the area is kept unity. Since unirradiated hDNA sample $I$ is eluted out at the void volume, its chromatogram shows an apparently sharp peak. The molecular weight seems to decrease with the increase in irradiation time, since the chromatogram of a sample irradiated at a 


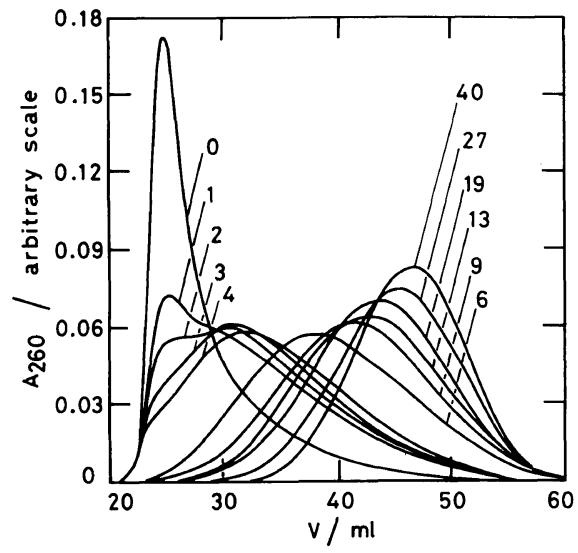

Figure 2. Dependence of the chromatogram profile of sonicated DNA on irradiation time. The area of each chromatogram was normalized to unity. Sonication was performed on an hDNA sample solution at $60 \mathrm{~W}$ with a small chip. A factor of thirty multiplied to each numeral gives the irradiation time in seconds. Added volume of soncated DNA solution, $0.6 \mathrm{ml}$; eluant, $0.2 \mathrm{M} \mathrm{NaCl}$; gel, Sephacryl S-1000 Superfine.

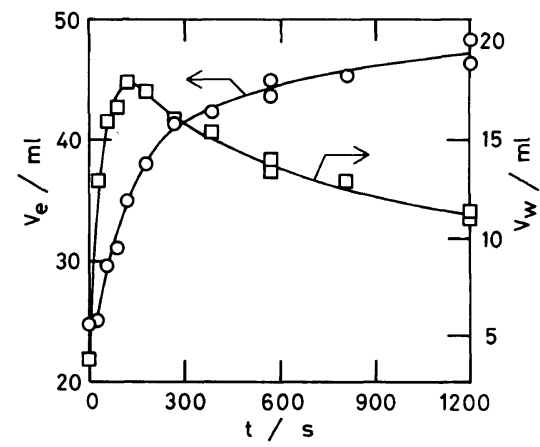

Figure 3. Dependence of the elution volume of the chromatogram peak $V_{\mathrm{e}}(\bigcirc)$ and the half intensity width $V_{\mathrm{w}}(\square)$ on irradiation time $t$. Note that values of $V_{\mathrm{e}}$ and $V_{\mathrm{w}}$ were evaluated from the data in Figure 2.

longer time is eluted more slowly.

Changes in chromatograms can be compared quantitatively by plotting the elution volume of the chromatogram peak $V_{\mathrm{e}}$ and the half intensity width $V_{\mathrm{w}}$ against irradiation time. Figure 3 shows that values of $V_{\mathrm{e}}$ increase rapidly at an initial short irradiation period (less than $300 \mathrm{~s}$ ), and then gradually with a lower irradiation efficiency. Values of $V_{\mathrm{w}}$ reach an apparent maximum at an irradiation time

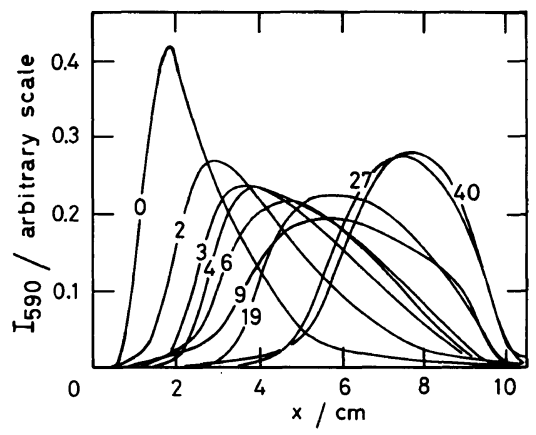

Figure 4. Dependence of the gel electrophoresis pattern of sonicated DNA on irradiation time. Each numeral corresponds to that of Figure 2 ( 1 and 13 are not shown). DNA samples are also the same as those in Figure 2.

of $120 \mathrm{~s}$, decreasing gradually thereafter. This maximum corresponds to samples irradiated between $120 \mathrm{~s}$ and $180 \mathrm{~s}$, indicating that the molecular weight distribution of sonicated DNA may be widest in this time range. A further irradiation makes the distribution apparently narrower. Both $V_{\mathrm{e}}$ and $V_{\mathrm{w}}$ appear to approach some constant values after prolonged irradiation. This trend is not an artifact, because a sonicated sample with the largest elution volume $\left(V_{\mathrm{e}}=50.7 \mathrm{ml}\right)$ was eluted faster than two small-molecular-weight markers, sodium benzenesulfonate and disodium adenosine-5'-triphosphate.

Gel Electrophoresis Patterns. The molecular weight degradation of an hDNA sample was also examined in the course of irradiation by gel electrophoresis in a manner similar to GPC. Figure 4 shows gel electrophoresis patterns of the fractions which were sampled at various irradiation times. The fluorescence intensity $I_{590}$ of each ethidium-bromide-stained gel plate, measured at successive points, is plotted against the migration distance $x$ from the gel slot to the points (see EXPERIMENTAL). The main features are similar to those of GPC, e.g., the migration distance $x$ for a sample sonicated at longer irradiation time is further away, indicating a further decrease in molecular weight. The elec- 
trophoresis pattern of a sonicated DNA sample is diffused in contrast with the sharp bands exhibited by the $\lambda$ phage DNA fragments digested with restriction enzymes. This is because a molecular weight distribution is present in the sonicated sample. Therefore, the distribution must be taken into account in determining the molecular weight by the electrophoretic method (and also by the GPC method).

\section{Determination of Molecular Weight and the Distribution}

By taking the electrophoretic method as an example, the molecular weight $M(x)$ of a sonicated sample and the molecular weight distribution function based on the weight of molecule, $f_{w}(x)$, at a given migration distance $x$, may be related to the fluorescence intensity, $I(x)$, as follows: ${ }^{28,30}$

$$
I(x) \mathrm{d} x \propto f_{w}(M(x)) \mathrm{d} M(x) \propto f_{w}(M(x)) \frac{\mathrm{d} M(x)}{\mathrm{d} x} \mathrm{~d} x
$$

$M(x)$ can be determined by comparing the migration distances of the bands of the DNA fragments whose molecular weights are known (e.g., HaeIII-digested $\phi$ X174 DNA). From eq 1 , the following is derived;

$$
f_{w}(M) \propto I(x) \frac{\mathrm{d} x}{\mathrm{~d} M}
$$

Hence, the electrophoretic pattern is transformed into the molecular weight distribution $f_{w}(M)$. From eq 2, the weight-average and number-average molecular weights, $M_{w}$ and $M_{n}$, are given as

$$
\begin{aligned}
M_{w} & =\frac{\int M f_{w}(M) \mathrm{d} M}{\int f_{w}(M) \mathrm{d} M}=\frac{\int M I(x) \frac{\mathrm{d} x}{\mathrm{~d} M} \mathrm{~d} M}{\int I(x) \frac{\mathrm{d} x}{\mathrm{~d} M} \mathrm{~d} M} \\
& =\frac{\int M(x) I(x) \mathrm{d} x}{\int I(x) \mathrm{d} x}
\end{aligned}
$$

and

$$
M_{n}=\frac{\int f_{w}(M) \mathrm{d} M}{\int \frac{f_{w}(M)}{M} \mathrm{~d} M}=\frac{\int I(x) \mathrm{d} x}{\int \frac{I(x)}{M(x)} \mathrm{d} x}
$$

Figure 5 shows the relationship between the molecular weight distribution $f_{w}$ and the number of base pairs, $n$, for each fragment of sonicated DNA samples (the molecular weight $M$ is given by $n \times 660$ ). It is now clear that the molecular weight of a sonicated sample decreases with an increase of irradiation time. The distribution curve of each sonicated DNA sample shows a single peak regardless of the irradiation period. This is in contrast with the finding of Smith and his coworkers that a single-peaked polystyrene sample exhibits a double-peaked molecular weight distribution pattern after ultrasonic irradiation. ${ }^{31,32}$ Such a result was not observed for DNA in this work. It should be noted, however, that the unsonicated hDNA sample shows a small second peak on the lower molecular side. This is probably due to a slight contamination of sheared smaller components. With the increase in irradiation time, fragments with about 200 base pairs $\left(M \fallingdotseq 1.32 \times 10^{5}\right)$ increase but those with less than 200 base pairs result only in small amounts. Therefore, there probably exists a lower limit of molecular weight in the sonicated fragments.

In order to make the above findings clearer, the number-average molecular weights, $M_{n}$, of samples sonicated for different periods of time at $60 \mathrm{~W}$ were calculated with aid of eq 4 . The results are shown in Figure 6. Under the experimental conditions employed in the present work, it was found that an hDNA is scissored effectively within 10 minutes of irradiation and, thereafter, values of $M_{n}$ approach gradually to a constant level of $2 \times 10^{5}$.

\section{Dependence of Intrinsic Viscosity of Sonicated DNA on Irradiation Energy}

Figure 7 shows the relationship between the 


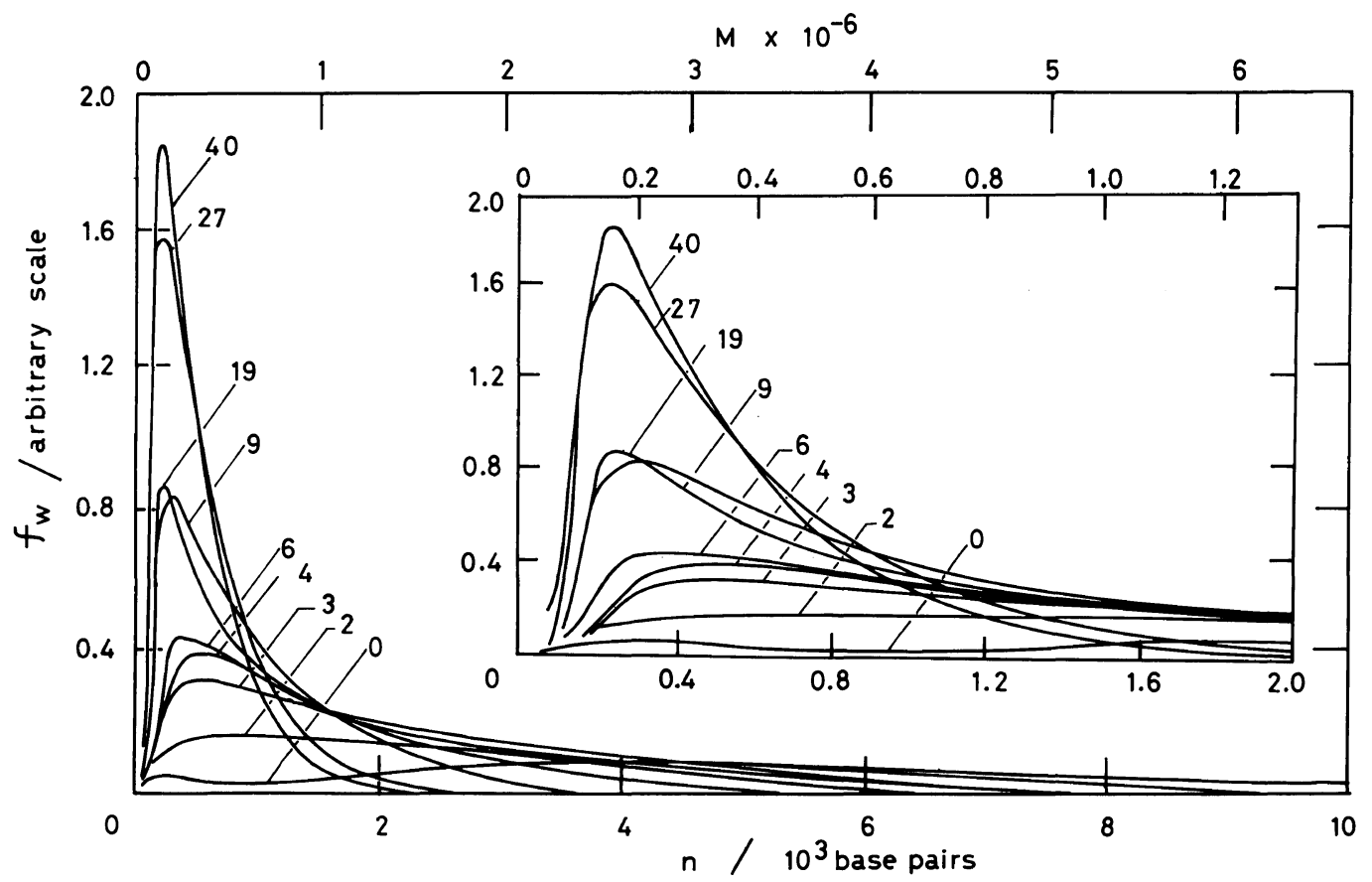

Figure 5. Dependence of the molecular weight distribution of sonicated DNA on irradiation time. $f_{\mathrm{w}}$ was evaluated from the data in Figure 4. Numerals in Figure are the same as those cited in Figure 2. Insert: an enlarged scale.

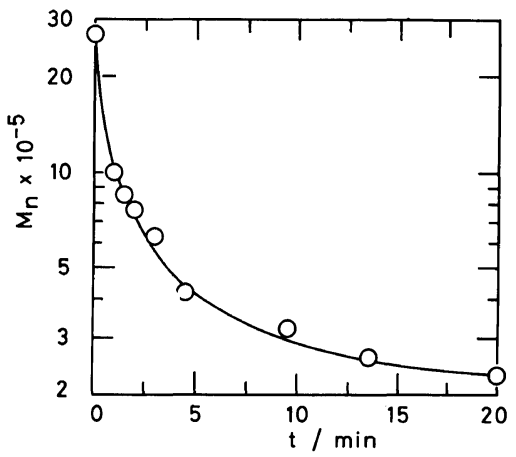

Figure 6. Dependence of the number-average molecular weight $M_{n}$ of sonicated DNA samples on irradiation time. Sample solutions are the same as those in Figure 4. Values of $M_{n}$ were evaluated from the gel electrophoresis pattern.

intrinsic viscosity, $[\eta]$, of irradiated DNA solutions and the sonic energy applied to the solution per unit volume, where the energy $U$ is defined as the (irradiation intensity $W) \times($ irradiation time $t) /($ volume of a DNA

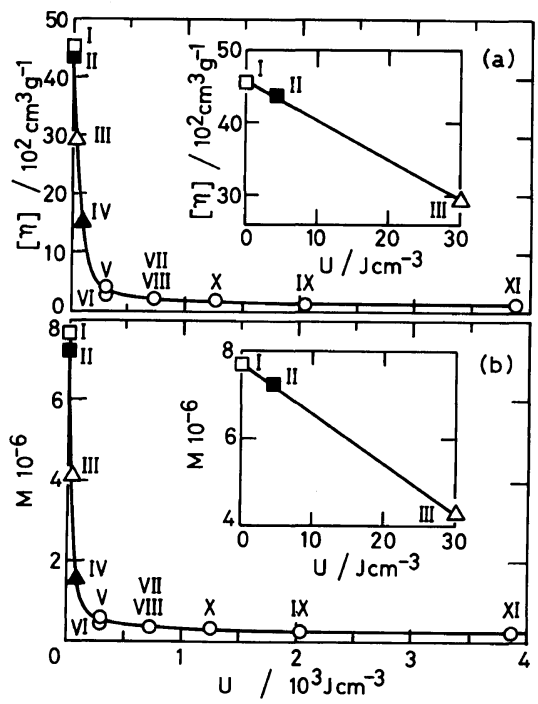

Figure 7. The relationship between the intrinsic viscosity $[\eta]$ and molecular weight $M_{w}$ of sonicated samples and the irradiation energy $U$. Roman numerals in Figure correspond to the sample numbers (cf. Table I). (a): the $[\eta]$ vs. $U$ plot. (b): the $M_{w}$ vs. $U$ plot. Irradiation times in seconds are: $\square, 0 ; \boldsymbol{\square}, 20 ; \Delta, 60 ; \boldsymbol{\Delta}, 90 ; \bigcirc$, 1200. 
solution). Values of $[\eta]$ of sonicated DNA solutions decrease rapidly with the increase in radiation energy $\left(U \leq 2000 \mathrm{~J} \mathrm{~cm}^{-3}\right)$, approaching a constant value. At very weak energies, the $[\eta] v s . U$ plots seem to be linear ( $c f$. insert). The molecular weight of each sonicated DNA sample was estimated from the intrinsic viscosity by using the Eigner and Doty formulas: ${ }^{24}[\eta]=1.05 \times 10^{-7} M_{w}^{1.32}\left(M_{w}<2 \times 10^{6}\right)$ and $[\eta]=6.9 \times 10^{-4} M_{w}^{0.70}\left(M_{w}>2 \times 10^{6}\right)$. The molecular weights of samples IX and XI were degraded to be as low as ca. $2 \times 10^{5}$; a 33 fold decrease of the original unirradiated hDNA whose contour length is $c a .40000 \AA$. Since a double-helical DNA of $2 \times 10^{5}$ corresponds to a length of $1000 \AA$, the sonication clearly produces short, rodlike DNA samples suited for the solution conformation study. The results in Figure 7 would be useful to select the irradiation conditions for this purpose, provided that the same sonicator and experimental conditions as specified in the present work are utilized.

\section{CONCLUSION}

By irradiating high molecular weight hDNA solutions with ultrasonic wave with different energies, the molecular weights could be lowered. Since both sonicated and unirradiated DNA samples showed hyperchromicity of about the same value, the double-stranded helical structure was concluded to be intact. From the GPC and electrophoretic results, it was found that the efficiency of scission levels off at prolonged irradiation but the molecular weight distribution becomes narrower. The results of viscosity led to the conclusion that the molecular weight of sonicated DNA depends on the irradiation energy. Thus, it became possible to prepare the sonicated DNA of desired molecular weights in large quantities by changing the radiation energy.

Acknowledgement. Many thanks are due to Miss I. Fuji for her skilled assistance in pursuing electrophoretic experiments.

\section{REFERENCES}

1. A. M. Basedow and K. H. Ebert, Adv. Polym. Sci., 22, 83 (1977).

2. N. Sata and M. Okuyama, Z. Elektrochem., 58, 196 (1954).

3. M. Okuyama, Z. Elektrochem., 59, 565 (1955).

4. H. H. G. Jellinek and G. White, J. Polym. Sci., 6, 745 (1951).

5. H. H. G. Jellinek and G. White, J. Polym. Sci., 6, 757 (1951).

6. D. W. Ovenall, G. W. Hastings, and P. E. M. Allen, J. Polym. Sci., 33, 207 (1958).

7. D. W. Ovenall, J. Polym. Sci., 42, 455 (1960).

8. P. Doty, B. B. McGill, and S. A. Rice, Proc. Natl. Acad. Sci. U.S.A., 44, 432 (1958).

9. D. Freifelder and P. F. Davison, Biophys. J., 2, 235 (1962).

10. O. C. Richards and P. D. Boyer, J. Mol. Biol., 11, 327 (1965).

11. N. J. Pritchards, D. E. Hughes, and A. R. Peacocke, Biopolymers, 4, 259 (1966).

12. D. E. Hughes and W. L. Nyborg, Science, 138, 108 (1962).

13. A. Obrenovitch and G. Aubel-Sadron, J. Chim. Phys.-Chim. Biol., 68, 521 (1971).

14. D. Londos-Gagliardi, G. Serros, and G. AubelSadron, J. Chim. Phys.-Chim. Biol., 68, 666 (1971).

15. D. Londos-Gagliardi, G. Serros, and G. AubelSadron, J. Chim. Phys.-Chim. Biol., 68, 670 (1971).

16. M. T. Record, Jr., C. P. Woodbury, and R. B. Inman, Biopolymers, 14, 393 (1975).

17. J. E. Godfrey, Biophys. Chem., 5, 285 (1976).

18. J. E. Godfrey and H. Eisenberg, Biophys. Chem., 5, 301 (1976).

19. A. W. Davis and D. R. Phillips, Biochem. J., 173, 179 (1978).

20. E. Charney and K. Yamaoka, Biochemistry, 21, 834 (1982).

21. U. Bertazzoni, Biochim. Biophys. Acta, 395, 239 (1975).

22. R. G. Kirste, Discuss. Faraday Soc., 49, 51 (1970).

23. J. B. T. Aten and J. A. Cohen, J. Mol. Biol., 12, 537 (1965).

24. J. Eigner and P. Doty, J. Mol. Biol., 12, 549 (1965).

25. N. C. Stellwagen, Biopolymers, 20, 399 (1981).

26. S. Zamenhof in "Methods in Enzymology," vol. 3, S. P. Colowick and N. O. Kaplan, Ed., Academic Press, New York, N. Y., 1975, p. 696.

27. J. Eigner, Doctoral Thesis, Harvard University, 1960.

28. O. Yamamoto, M. Ogawa, and M. Hoshi, J. Radiat. Res., 23, 385 (1982).

29. J. Applequist and V. Damle, J. Am. Chem. Soc., 87, 1450 (1965). 


\section{K. FUKudome et al.}

30. S. Chiu and N. L. Oleinick, Radiat. Res., 82, 146 (1982).

31. W. B. Smith and H. W. Temple, J. Phys. Chem., 72,

4613 (1968).

32. J. A. May, Jr., and W. B. Smith, J. Phys. Chem., 72, 216 (1968). 